\title{
Table des matières - Inhaltsverzeichnis
}

Preface des Éditeurs .......................................................................................................

Klaus-Jürgen Müller

Einleitung

Les grandes puissances entre la France et l'Allemagne -

Großmächte zwischen Frankreich und Deutschland

\section{Klaus Schwabe}

Die Vereinigten Staaten und die Sicherheit Frankreichs 1918-1955.

Georges-Henri Soutou

La place de l'URSS dans la politique allemande de la France 1943-1969.

Roland Höhne

Die Bedeutung der Sowjetunion für die deutsch-französischen Beziehungen

1970-1991

\section{Cyril Buffet}

„Une étrange histoire d'amour": Le facteur britannique dans les relations francoallemandes 1945-1963.

Les moyennes et petites puissances entre la France et

l'Allemagne - Mittlere und kleinere Mächte zwischen

Frankreich und Deutschland

Raymond Poidevin

Les États balkaniques théâtres d'affrontement entre intérêts français et allemands avant 1914

Gilbert Trausch

Luxemburg als Dritter zwischen Deutschland und Frankreich

Pierre Guillen

L'Italie dans les relations franco-allemandes au début du XXe siècle 1904-1915

François Roth

La Belgique dans les rapports franco-allemands au moment de l'affaire de la

Ruhr..... 
Ilja Mieck

Der Einfluß der „Orientalischen Frage“ auf die französisch-preussischen

Beziehungen im 19. Jahrhundert

Heinrich Küppers

Der Faktor Polen in der deutschen Frankreichpolitik 1918-1934

Facteurs transnationaux et médiations culturelles Transnationale Faktoren und kulturelle Vermittlungen

Louis Dupeux

Communisme et patriotisme en France et en Allemagne de 1919 à 1939

François-Georges Dreyfus

Les Protestantismes entre la France et l'Allemagne 1850-1933

Annie Lacroix-Riz

Le Vatican, la France et l'Allemagne après les deux guerres mondiales

Heidrun Homburg

Industrielle Rationalisierung zwischen Politik und nationaler Kultur:

Eine deutsche und französische Sicht auf das amerikanische Modell

in den 1920er Jahren

Dieter Tiemann

Deutsche Jugend zwischen Ost und West - ein Aspekt der Diskussionen um

Kulturtransfer Ende der 20er, Anfang der 30er Jahre

Werner Scholz

Das deutsch-französische Verhältnis in den internationalen Kulturorganisationen der Zwischenkriegszeit

Participants au Colloque de Paray-le-Monial

Teilnehmer an dem Kolloquium in Paray-le-Monial

Index 